\title{
The effect of self-sampled HPV testing on participation to cervical cancer screening in Italy: a randomised controlled trial (ISRCTN9607|600)
}

\author{
P Giorgi Rossi ${ }^{*, 1}$, LM Marsili ${ }^{2}$, L Camilloni', A lossa ${ }^{3}$, A Lattanzi ${ }^{4}$, C Sani $^{3}$, C Di Pierro ${ }^{3}$, G Grazzini $^{3}$, \\ C Angeloni ${ }^{4}$, P Capparucci ${ }^{2}$, A Pellegrini $^{5}$, ML Schiboni $^{5}$, A Sperati $^{1}$, M Confortini $^{3}$, C Bellanova $^{2}$, A D'Addetta $^{2}$, \\ E Mania $^{2}$, CB Visioli ${ }^{3}$, E Sereno ${ }^{3}$, F Carozzi $^{3}$ and the Self-Sampling Study Working Group ${ }^{6}$ \\ 'Agency for Public Health, Lazio Region, Via di S Costanza 53, Rome 00198, Italy; 'Local Health Unit ASL RMC, Via Monza 2A, Rome 00182, Italy; \\ ${ }^{3}$ ISPO, Cancer Prevention and Research Institute, Viale A Volta 17I. Florence 50 I31, Italy; ${ }^{4}$ Coordinamento Programmi di Screening Regione Abruzzo, \\ Ospedale di Atri, Italy; ${ }^{5}$ San Giovanni Hospital, Via dell'Amba Aradam 9, Rome 00184, Italy
}

BACKGROUND: In Italy, cervical cancer screening programmes actively invite women aged 25-64 years. Programmes are hindered by low participation.

METHODS: A sample of non-responder women aged 35-64 years, belonging to three different programmes (in Rome, Florence and Teramo), was randomly split into four arms: two control groups received standard recall letters to perform either Pap-test (first group) or human papillomavirus (HPV) test (second group) at the clinic. A third arm was sent letters offering a self-sampler for HPV testing, to be requested by phone, whereas a fourth group was directly sent the self-samplers home.

RESULTS: Compliance with standard recall was 13.9\% (N6|9). Offering HPV test at the clinic had a nonsignificant effect on compliance $(\mathrm{N} 616$, relative risk $(\mathrm{RR})=1.08 ; 95 \% \mathrm{Cl}=0.82-1.41)$. Self-sampler at request had the poorest performance, $8.7 \%(\mathrm{~N} 622$, $\mathrm{RR}=0.62 ; 95 \% \mathrm{Cl}=0.45-0.86$ ), whereas direct mailing of the self-sampler registered the highest compliance: 19.6\% (N6I6, $R R=1.41 ; 95 \% \mathrm{Cl}=1.10-1.82)$. This effect on compliance was observed only in urban areas, Florence and Rome (N438, RR=1.69; $95 \% \mathrm{Cl}=1.24-2.30)$, but not in Abruzzo $(\mathrm{NI} 78, \mathrm{RR}=0.95 ; 95 \% \mathrm{Cl}=0.6 \mathrm{I}-1.50)$, a prevalently rural area.

CONCLUSIONS: Mailing self-samplers to non-responders may increase compliance as compared with delivering standard recall letters.

Nevertheless, effectiveness is context specific and the strategy costs should be carefully considered.

British Journal of Cancer (20II) I 04, 248-254. doi:I0.1038/sj.bjc.6606040 www.bjcancer.com

Published online 21 December 2010

(c) 201। Cancer Research UK

Keywords: Pap-test; HPV test; screening programme; cervical cancer prevention

Testing for human papillomavirus (HPV) DNA in the cervix has been shown to be an effective mean for cervical cancer prevention in large population trials carried out in different countries with huge differences in social, cultural and economical background (Bulkmans et al, 2007; Naucler et al, 2007; Sankaranarayanan et al, 2009; Ronco et al, 2010). Human papillomavirus test is more sensitive than conventional Pap-test (Cuzick et al, 2006, 2008 ), giving a longer protection in case of negative results, and the overdiagnosis can be controlled at least in women aged 35 years and older (Bulkmans et al, 2007; Naucler et al, 2007; Sankaranarayanan et al, 2009; Ronco et al, 2010).

Even if an increase in test sensitivity is welcome, this is not the main problem in cervical cancer prevention. In fact, in most industrialised countries, the majority of invasive cancers occurs in never-screened or under-screened women (van der Graaf et al, 1988; Ciatto et al, 1993; Janerich et al, 1995; Sasieni et al, 1996; Sung et al, 2000; Leyden et al, 2005; Morrell et al, 2005; Bos et al, 2006; Ingemann-Hansen et al, 2008). As a consequence, the

*Correspondence: Dr P Giorgi Rossi; E-mail: giorgirossi@asplazio.it

${ }^{6}$ See Appendix for details on the working group.

Received 10 September 2010; revised 2 November 2010; accepted II

November 2010; published online 21 December 2010 heaviest and most immediate impact on cervical cancer prevention can be obtained only by improving the test coverage (IARC, 2005; Arbyn et al, 2008).

In Italy, more than two-thirds of the female population aged $25-64$ years is covered by screening programmes that actively invite the whole target population by mail every 3 years. Compliance with invitation is low, about $40 \%$ (Ronco et al, 2008). Nevertheless, the test coverage is estimated to be quite high, $>70 \%$ (data from National Health Interview (ISTAT, 2006) and PASSI study (PASSI, 2009)), owing to opportunistic testing by private and public gynaecologists. Furthermore, wide variations in test coverage are observed among regions, ranging from 48 to $88 \%$ (ISTAT, 2006).

The use of HPV DNA test as primary screening test allows for the introduction of self-sampling (Wright et al, 2000; Nobbenhuis et al, 2002; Sanner et al, 2009; Gök et al, 2010), whereas conventional Pap-test requires sampling to be performed by a health professional. The opportunity of a home, self-collected sample, opens the chance to remove some of the barriers that may discourage women from participating to screening programmes or performing Pap-test. Self-sampling is less time consuming and invasive as compared with tests performed at a clinic. It allows for privacy, reduces discomfort and women know nobody would have to handle their body. 
The objective was to measure the effect on test compliance of introducing a self sampler device using different strategies.

\section{POPULATION AND METHODS}

\section{Setting}

The study was performed within three organised screening programmes from three different Italian regions: Florence (Tuscany), Rome southern city (Lazio) and Teramo (Abruzzo). In these areas, programmes actively invite all the resident female population aged 25-64 years for a Pap-test every 3 years.

\section{Study population}

Women aged 35-65 years who had been invited by the screening programme in the previous months and had failed to respond were eligible for mail recall. Each programme has a different strategy for recall: in Florence, recalls are sent to all non-responding women after invitations for a whole district are completed, which is to say after a period of at least 3 months and not more than 5 months. In Rome and Teramo, recalls are automatically mailed to nonresponders 3 months after the invitation.

\section{Study design}

A random sample of 2480 eligible women was randomly assigned to one of the following arms (Figure 1):

(1) two control arms with a standard invitation letter to perform either a Pap-test (a) or an HPV test (b) at the clinic on a pre-fixed date;

(2) two intervention arms:

(2.1) a group was offered the opportunity to receive the self-sampler device (PantaRhei Devices, Zeist, the Netherlands) (Brink et al, 2006) (by mail or picking it up at the clinic). If interested, women had to call a free toll number.
(2.2) another group was directly sent the self-sampler, announced by a letter a week before.

The lists of eligible women were provided by the centres. When known, women of the same household were identified with a flag and randomised as a unique item to the same arm (we decided not to account for this in the analysis owing to the extremely low number of these couples). Random sampling and arm assignment were performed centrally by the coordinating centre (Rome) using STATA 8.2 (StataCorp, College Station, TX, USA) and putting as seed for random number generator the first number drawn by the most recent National Lottery: four consecutive samples of the predetermined size of independent statistical units were drawn and assigned to the corresponding arm. Couples of women resident in the same address were randomised as a single statistical unit.

The planned sample size was 200 women per arm per centre. This would allow for $80 \%$ power to detect, with $95 \%$ confidence, a $7 \%$ increase in compliance, in the hypothesis of $15 \%$ compliance in the control arm. Sampling started in Rome, with the very sample size as previously planned (800). As a result, extra self-sampler boxes were available for the study in Florence, in which the sample size was slightly increased ( 235 per arm $=940$ total). In Abruzzo, we later planned an additional fifth arm, slightly decreasing the number of women in the four arms (180 per arm). Actually the fifth arm was implemented as a separate trial, a few months after this study, owing to the earthquake that destroyed part of the Abruzzo region in April 2009.

\section{Description of the intervention}

In the two control arms, the intervention was only the recall letter inviting for a Pap smear (arm (a)) or an HPV test (arm (b)) at a prefixed date at the clinic.

In the arm with the self-sampler at request, we mailed a letter inviting women to dial a free-toll number to receive the self-sampling device and an information leaflet on HPV test and cervical cancer. We offered women two opportunities: to either

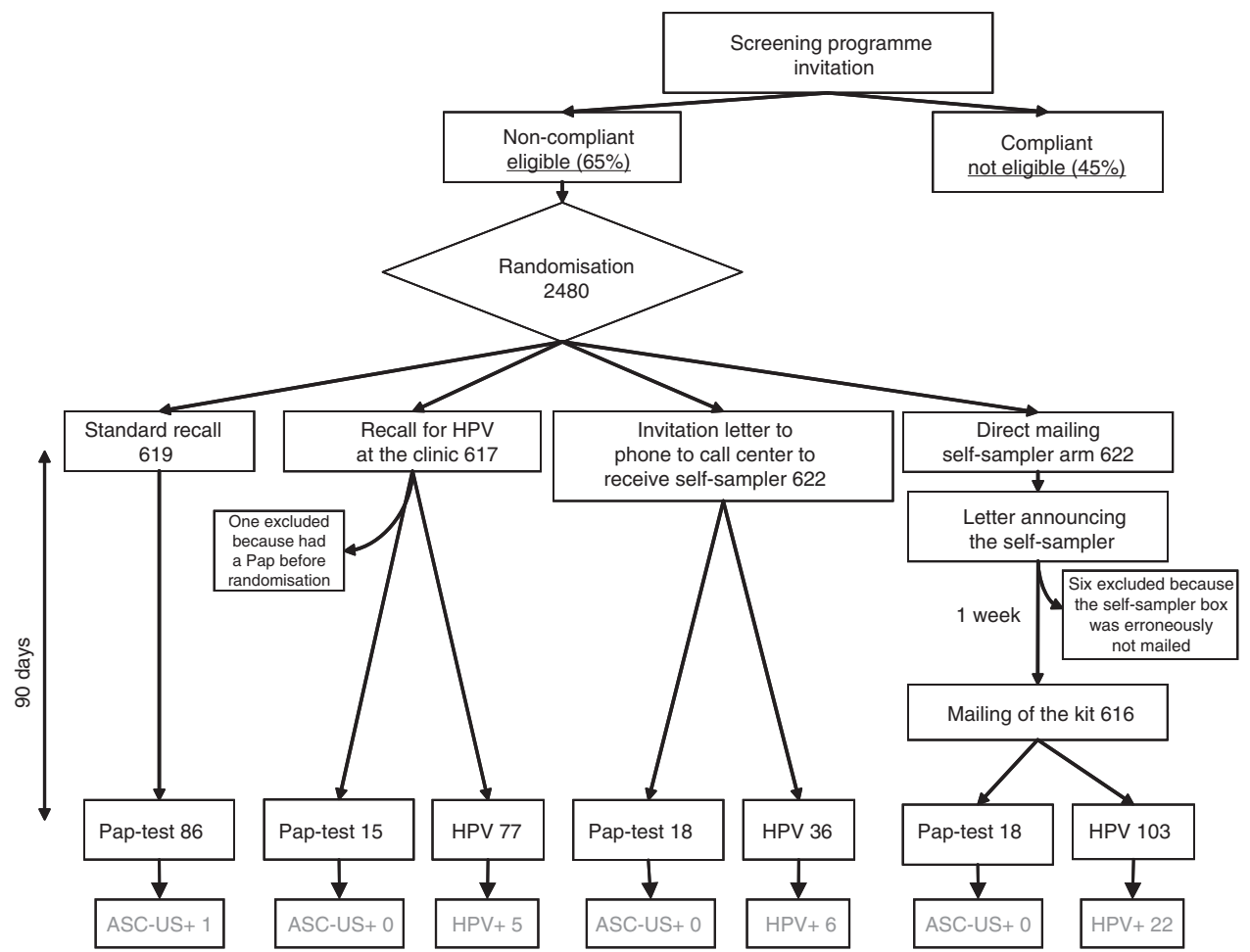

Figure I Flowchart of the study design. ASC-US +, women with cytology atypical squamous cells of unknown significance or more severe; HPV + , women with high-risk HPV DNA test positive. 
have the device shipped home or pick it up by themselves at the clinic. The self-sampler box contained the following items:

- a presentation letter;

- a leaflet about HPV test and cervical cancer prevention;

- the informed consent form to perform the test and to be contacted by phone in case of positivity;

- the self-sampler device;

- the instructions for the device use;

- a tube and a pre-paid envelope to mail of the sample; and

- a short questionnaire asking the approximate date of the latest Pap-test, questions about the sampling (if it was easy, annoying, embarrassing) and the date of sampling.

In the arm with the direct mailing, we sent an alerting letter explaining that the local Public Screening Program would provide women with a box containing a self-sampler device completely free. After 1 week, we shipped the box, containing the same items listed above.

Questionnaires slightly differed among centres owing to length constrains and local priorities. In this study, we analyse only the questions that were almost identical in the three versions: date of women's latest Pap-test, reason for non-compliance with the screening programme (only Rome and Florence), questions about the self-sampling performance (pain, embarrassment, feasibility), what was mostly appreciated in the self-sampling (doing it by themselves, privacy, absence of a doctor, absence of speculum), which kind of sampling was preferred (i.e., self-performed or carried out at the clinic).

\section{Management of HPV-positive women}

All women who resulted in being HPV positive were contacted by phone and letter to propose a counselling on HPV and cervical cancer risk and a colposcopy. If the colposcopy was positive, a biopsy was taken, and if colposcopy was negative, women were suggested to undergo control with Pap-test within a year's time.

\section{Outcome}

The main outcome we took into consideration was women's participation in screening: all women who accepted to perform a test in the screening programme within 3 months from the first letter mailing were considered a success.

A secondary outcome was the impact on cervical cancer screening coverage, measured as the number of women nevercovered or under-covered (latest test performed longer than 3 years earlier) for whom we obtained a cervical sample.

Other secondary outcomes were HPV positivity rate and detection rate for $\mathrm{CIN} 2+$ in the intervention arm.

\section{Laboratory methods}

Samples pretreatment When samples arrived at the laboratory, they were centrifuged at $500 \mathrm{~g}$ for $10 \mathrm{~min}$. Supernatants were discarded and pellets suspended in $1 \mathrm{ml}$ of STM (Specimen Transport Medium; Qiagen, Hilden, Germany). Before performing $\mathrm{Hr}$-Hybrid Capture 2 (HC2), $200 \mu \mathrm{l}$ aliquots were stored at $-80^{\circ} \mathrm{C}$.

HPV testing and evaluation of sample adequacy Highrisk (HR) HPV was evaluated by HC (Qiagen), using only the B probe mix, which is specific for $12 \mathrm{HR}$ HPV types: $16,18,31,33,35,39,45,51$, $52,56,58,59$ and one probably carcinogenic HPV type: 68 (Bouvard et al, 2009). The recommended positivity threshold of $1 \mathrm{pg} \mathrm{ml}^{-1}$ (equivalent to 5000 viral copies per test well) was used as a cutoff control value, and all samples with an RLU/Control ratio $\geqslant 1.00$ were considered HR-HPV positive.

In Florence, all HC2-negative samples were further analysed to evaluate sample adequacy. DNA was extracted from $200 \mu \mathrm{l}$ of un-denaturated STM samples with QIAamp DNAMini kit (Qiagen) according to the manufacturer's instruction. Amplification of the human $\beta$-globin gene was performed using GH20-PC04 primers (268-bp amplicon length) (Bauer et al, 1992). One HPV-negative sample was included in each batch of extraction to exclude any contamination. Polymerase chain reaction products were run on $2 \%$ ethidium bromide-stained agarose gels and visualised by ultraviolet light.

\section{Analysis}

We adopted an intention-to-treat analysis: women were considered as participating, independently of the randomisation arm, if they provided any kind of sample (Pap smear, STM or self-collected liquid sample), in any setting (home or screening clinic).

We report the relative risk (RR) of having a test comparing each intervention arm with the two controls. Participating centres samples were pooled if there was no heterogeneity.

We used the information collected with questionnaires to calculate the impact on population coverage of each strategy according to the following formula:

((under-covered respondents)/(total randomised sample)) $\times$ (proportion of non responders at first invitation).

\section{RESULTS}

Nine hundred and fifty-one women were randomised in Florence, 800 in Rome and 729 in Abruzzo. Six women were excluded after randomisation in the direct mailing arm because the kit was not mailed owing to a logistical mistake and one was excluded because she had had a Pap-test in the screening programme before randomisation, but it had been notified to the coordinating centre just after the study started.

Table 1 shows the compliance by arm and by centre.

\section{Effect on compliance}

The compliance with standard recall was $13.9 \%$, similar to that obtained with a standard letter inviting women to perform HPV test at the clinic (14.9\%). The group which received the selfsampler on demand had a poorer performance as compared with the standard recall letter arm, RR $0.62(95 \% \mathrm{CI}=0.45-0.86)$ with no differences among centres. The self-sampler direct mailing strategy had, on average, a higher performance and increased compliance by $40 \%(\mathrm{RR} 1.41,95 \% \mathrm{CI}=1.10-1.82)$ with respect to standard recall, but it showed a border line significant heterogeneity among centres. In fact, the positive effect was detectable only in urban areas, Rome and Florence, whereas in Abruzzo, a prevalently rural, small town area, no positive effect was detected.

\section{Positivity rate and detection rate}

In the direct mailing arm, according to the dates reported in the questionnaires, the median time elapsed from the sampling and the laboratory check in for the specimen was 4 days and only one sample took longer than 1 week (8 days). Nevertheless, in Abruzzo, where the kits were mailed in July with very high environmental temperatures, some specimens looked contaminated by a strong bacterial growth and two samples were unsatisfactory.

The overall positivity rate among the self-collected samples in the direct mail arm was $21.8 \%$ (22 out of 101). All but two women accepted to perform a colposcopy (91\%) and no CIN2 + was found. The positivity rate in the HPV control arm was $6.5 \%$ (5 out of 77), and the difference was statistically significant $(P=0.006)$. 
Table I Compliance by arm and type of test

\begin{tabular}{|c|c|c|c|c|c|c|c|c|c|c|}
\hline Intervention & $\begin{array}{l}\text { Invited } \\
\text { women }\end{array}$ & $\begin{array}{l}\text { Test } \\
\text { HPV }\end{array}$ & Pap-test & $\underset{(\%)}{\text { Compliance }}$ & $\begin{array}{c}\text { RR vs } \\
\text { Pap-test }\end{array}$ & $95 \% \mathrm{Cl}$ & $\begin{array}{c}\text { Test for } \\
\text { heterogeneity }\end{array}$ & $\begin{array}{l}\text { RR vs } \\
\text { HPV }\end{array}$ & $95 \% \mathrm{Cl}$ & $\begin{array}{c}\text { Test for } \\
\text { heterogeneity }\end{array}$ \\
\hline \multicolumn{11}{|l|}{ Total } \\
\hline Standard recall & 619 & 0 & 86 & 13.9 & | & & & 0.93 & $(0.7|-| .22)$ & 0.27 \\
\hline Self-sampling on demand & 622 & 36 & 18 & 8.7 & 0.62 & $(0.45-0.86)$ & 0.92 & 0.58 & $(0.42-0.80)$ & 0.22 \\
\hline Self-sampling direct mailing & 616 & 103 & 18 & 19.6 & $1.4 \mid$ & $(1.10-1.82)$ & 0.11 & 1.32 & $(1.03-1.68)$ & 0.01 \\
\hline HPV at the clinic & 616 & 77 & 15 & 14.9 & 1.08 & $(0.82-1.41)^{\prime}$ & 0.27 & 1 & & \\
\hline \multicolumn{11}{|l|}{ Florence } \\
\hline Standard recall & 238 & 0 & 34 & 14.3 & I & & & 0.76 & $(0.50-1.14)$ & \\
\hline Self-sampling on demand & 240 & 12 & 9 & 8.8 & 0.61 & $(0.37-1.02)$ & & 0.47 & $(0.29-0.76)$ & \\
\hline Self-sampling direct mailing & 238 & 45 & 8 & 22.3 & 1.56 & $(1.05-2.31)$ & & 1.18 & $(0.83-1.69)$ & \\
\hline HPV at the clinic & 234 & 40 & 4 & 18.8 & 1.32 & $(0.87-1.98)^{\prime}$ & & 1 & & \\
\hline \multicolumn{11}{|l|}{ Rome } \\
\hline Standard recall & 200 & 0 & 20 & 10.0 & I & & & 1.43 & $(0.74-2.75)$ & \\
\hline Self-sampling on demand & 200 & 12 & 2 & 7.0 & 0.70 & $(0.36-1.35)$ & & 1.0 & $(0.49-2.04)$ & \\
\hline Self-sampling direct mailing & 200 & 36 & 2 & 19.0 & 1.90 & $(1.15-3.15)$ & & 2.71 & $(1.52-4.85)$ & \\
\hline HPV at the clinic & 200 & 14 & 0 & 7.0 & 0.70 & $(0.36-1.35)$ & & I & & \\
\hline \multicolumn{11}{|l|}{ Abruzzo } \\
\hline Standard recall & $|8|$ & 0 & 32 & 17.7 & | & & & 0.95 & $(0.61-1.46)$ & \\
\hline Self-sampling on demand & 182 & 12 & 7 & 10.4 & 0.59 & $(0.35-1.00)$ & & 0.56 & $(0.33-0.94)$ & \\
\hline Self-sampling direct mailing & 178 & 22 & 8 & 16.9 & 0.95 & $(0.61-1.50)$ & & 0.90 & $(0.58-|.4|)^{\prime}$ & \\
\hline HPV at the clinic & 182 & 23 & II & 18.7 & 1.06 & $(0.68-1.64)$ & & 1 & & \\
\hline
\end{tabular}

Abbreviations: $\mathrm{Cl}=$ confidence interval; $\mathrm{HPV}=$ human papillomavirus; $\mathrm{RR}=$ relative risk. Values given in bold indicate that $\mathrm{RR}$ is significantly different from I, $\mathrm{P}<0.05$.

The Pap-test ASCUS or more severe in the standard recall arm was one out of $86(1.2 \%)$. The woman had a colposcopy and no CIN2 + was found.

\section{Acceptability of the self-sampling device}

We collected 147 questionnaires. The most frequent reason for failing to comply with previous screening invitation was recent Pap-test $(40.6 \%)$. No woman declared that Pap-test is not important and only two of them declared that they did not perform the test because they were embarrassed (Table 2A). Table 2B shows the answers about the sampling: $88.3 \%(128)$ of women declared that the sampling was easy, only two reported that it was annoying and two reported that it was embarrassing. The most checked reasons for which they appreciated the self-sampling were 'to do the sampling by myself (57.6\%) and 'privacy' (49.3\%).

In the open answer questions, some women expressed concerns about the quality of self-collected samples, and six of them complained about broken devices (in all cases the sample was taken and analysed). No woman reported concerns about having the HPV viral test instead of the cytological test, nor about the way of infection.

\section{Impact on population coverage}

Only six women $(4.1 \%)$ referred to never having had a Pap-test before and five did not remember (3.4\%). Among the others, $12(8.2 \%)$ had had a test longer than 5 years before, and $45(30.8 \%)$ had had it between 3 and 5 years before.

The impact on coverage was computed only for Florence and Rome, the very places where a definite gain in coverage has been proved; and for the arm in which an increase in compliance as compared with standard recall has been observed: the direct mailing arm. Out of 91 women responding to the direct mailing of the kit in Florence and Rome, four had never had a Pap-test before and 30 were under-covered, that is, they had undergone a test longer than 3 years earlier, whereas the rest of women had had a Pap-test within 3 years. The proportion of not- or under-covered women on the total randomised sample is 34 out of $438(7.8 \%)$. This proportion must be applied to the population that had not responded to first invitation, that is, the eligible population for the
Table 2 Answer to questionnaires

(A) Reasons for non-compliance with screening programme invitation letter

\begin{tabular}{lcc}
\hline Reasons for non-compliance & N & $\%$ \\
\hline Recent Pap-test & 41 & 40.6 \\
No time & 23 & 22.8 \\
I did not receive the letter & 15 & 14.9 \\
I was out & 7 & 6.9 \\
I was pregnant & 6 & 5.9 \\
It is embarrassing & 2 & 2.0 \\
I think it is not useful & 0 & 0.0 \\
Other & 7 & 6.9 \\
Total & 101 & 100 \\
& & \\
\hline
\end{tabular}

(B) Attitudes to self-sampling

\begin{tabular}{|c|c|c|c|c|}
\hline & \multicolumn{2}{|c|}{ Yes } & \multirow{2}{*}{\multicolumn{2}{|c|}{$\begin{array}{c}\text { Total } \\
\mathbf{N}\end{array}$}} \\
\hline & $\boldsymbol{N}$ & $\%$ & & \\
\hline \multirow{3}{*}{$\begin{array}{l}\text { The sampling was } \\
\text { Easy } \\
\text { Annoying } \\
\text { Embarrassing } \\
\text { I was not sure I had a good sample } \\
\text { I appreciated } \\
\text { To do the sampling by myself } \\
\text { Not to be undressed in front of a doctor } \\
\text { The absence of speculum } \\
\text { Privacy }\end{array}$} & $\begin{array}{r}128 \\
2 \\
2 \\
17\end{array}$ & $\begin{array}{r}88.3 \\
1.4 \\
1.4 \\
11.8\end{array}$ & \multicolumn{2}{|c|}{$\begin{array}{l}\mid 45 \\
\mid 45 \\
\mid 45 \\
144\end{array}$} \\
\hline & $\begin{array}{l}83 \\
37 \\
45 \\
70\end{array}$ & $\begin{array}{l}57.6 \\
25.2 \\
31.5 \\
49.3\end{array}$ & & $\begin{array}{l}44 \\
47 \\
43 \\
42\end{array}$ \\
\hline & \multicolumn{2}{|c|}{ Self } & \multicolumn{2}{|c|}{ Clinic } \\
\hline Which sampling method do you prefer & $\mathbf{N}$ & $\%$ & $\mathbf{N}$ & $\%$ \\
\hline & 109 & 78.4 & 30 & 21.6 \\
\hline
\end{tabular}

trial. This proportion in Florence and Rome was 65\%. According to the formula proposed in the Population and Methods section, the impact of direct mailing on population coverage would be: $(34 / 438) \times 0.65=+5.1 \%(95 \% \mathrm{CI}=3.6-7.1)$. If we consider 
under-covered those who had had a Pap-test over 5 years earlier, the impact on compliance would then be $2.2 \%(95 \% \mathrm{CI}=1.2-3.7)$.

\section{DISCUSSION}

Our results show that delivering self-samplers may increase compliance with cervical cancer screening programmes. Even if the observed heterogeneity was not statistically significant, we must highlight that a positive effect on compliance was observed only in Florence and Rome. Many context factors might explain this difference: there could be cultural and behavioural differences between urban and rural areas, or there may be more logistical problems in shipping self-sampler boxes in rural areas owing to different shape or location of the mail boxes. Finally, in Abruzzo the trial was performed in mid-July, when compliance with screening programmes is usually low and decreases as we get nearer August, when most Italian families are on holidays. In this period, the additional week needed in the direct mailing arm may have had a strong negative influence on compliance. This delay in performing our analysis was owing to the above-mentioned earthquake hitting the Abruzzo region in April 2009, which halted all studies for weeks.

We only found one randomised controlled trial comparing the effect of using the self-sampler instead of the standard recall letter for conventional cytology on compliance with screening invitation (Gök et al, 2010).

Some non-randomised trials showed a potential impact to increase test uptake and feasibility on large scale (Belinson et al, 2003; Salmerón et al, 2003; Sanner et al, 2009; Ogilvie et al, 2007; Szarewski et al, 2007). Two systematic reviews (Petignat et al, 2007; Stewart et al, 2007) concluded that the accuracy of self-sampling-based HPV test makes it suitable as an alternative mean for cervical screening, and one review affirms (Stewart et al, 2007) that there is lack of evidence on its impact on compliance.

Our trial design allowed us to distinguish the effect of offering a new test, that is, HPV instead of Pap, and the effect of selfsampling. In fact, we compared the intervention arm to two different control letters: the standard one, inviting for a Pap-test, and a similar letter inviting women to an HPV test with the same modalities. In Rome and Abruzzo, the two controls had the same performance, but in Florence, the HPV control had an intermediate performance between the standard Pap-test recall letter and the direct mailing of the self-sampler. Even if the observed differences are not statistically significant, the results in Florence may suggest that, at least in that context, part of the increase in compliance could be owing to the appeal of the new test. It should be taken into account that Florence was one of the participating centres in NTCC trial (Ronco et al, 2006). Consequently, the awareness of the population about HPV may be higher in this area.

Our study was not designed to detect differences in positivity or detection rate, but the difference in positivity rate between the control HPV and the direct mailing arm, as well as the low positivity in the Pap-test arm, suggests that women responding to self-sampling may be at higher risk of HPV infection. The difference may be also owing to the sampling technique or to the transport medium making HCII with self-sampling less specific than that performed at the clinic. Previous studies observed only small differences in positivity rate in double sampling or randomised studies (Belinson et al, 2003; Salmerón et al, 2003; Brink et al, 2006). On the other hand, a higher risk in non-responding women has been reported in several studies (Ogilvie et al, 2007). In particular, Gök et al (2010) found a higher risk in women responding to self-sampling.

We did not face important logistical problems. Few kits were returned late by the postal provider, and no claims for privacy or other individual offences came from the women involved. On the other hand, we had some evidence that very high external temperature may be a problem for sample conservation during transport through standard mail.

\section{Acceptability}

The test was very well accepted by responding women, and the majority of them declared to prefer this way of sampling compared with the clinical sample. Pain and embarrassment were not problems at all, although some women declared it was not easy or that they were concerned about having collected the sample properly. The main reason to prefer self-sampling was the do-ityourself opportunity given by the device, but also the less frequently checked answers, the absence of speculum and the absence of a doctor, were chosen by a relevant proportion of women. These results are consistent with previous studies (Anhang et al, 2005; Waller et al, 2006). The reasons for failing to comply with screening invitation confirmed what was already known for Italy: opportunistic screening outside screening programmes is very widespread and logistical barriers interfere with compliance (lack of time, failure to receive the letter).

\section{Impact on population coverage}

In the self-sampling arms, the proportion of not- or under-covered women was quite high among those who accepted to perform the test: according to questionnaires, more than $43 \%$ of women had had a Pap longer than 3 years earlier. According to the National Health Interview and the PASSI survey (ISTAT, 2006; PASSI, 2009), in these areas the proportion of not- or under-covered (latest Pap-test $>3$ years before) women is much lower: $16 \%$ in Rome, $15 \%$ in Florence and $25 \%$ in Abruzzo. The difference is not surprising, as the eligible population in our study included only programme non-responders. The high Pap-test coverage in Florence and Rome is the effect of widespread opportunistic screening, both in the public and the private sector (Giorgi Rossi et al, 2006; ISTAT, 2006; PASSI, 2009). In this urban context, a 5\% increase brings the coverage up to $90 \%$. Considering that this estimate does not exclude virgins, and permanently sick women, and only partially accounts for hysterectomies, $90 \%$ may be considered a virtually full coverage.

Nevertheless, a $5 \%$ increase in coverage ( $2 \%$ if we only consider under-covered women with a Pap-test longer than 5 years earlier) is relevant in terms of public health. An increase in population Pap-test coverage of 1 or $2 \%$ is what has been obtained by most trials that measured the impact and not only the RR of the intervention vs control arms (Eaker et al, 2004; Corkrey et al, 2005; Jensen et al, 2009). The Danish Health Technology Assessment of cervical cancer found that an absolute increase in the coverage rate of $1 \%$ equals the risk reduction obtained by reducing the interval from 3 to 2 years and estimates a gain of 85 life-years each year in Denmark (Sundhedsstyrelsen et al, 2005).

If the absolute relevance of such a gain in population health is not questionable, the costs to obtain it must be carefully considered. In our trial, we had to send out five self-samplers to get one sample back to be tested. This number goes up to 13 if we consider the number needed to gain uncovered women to screening. Low response rate and high population coverage owing to overlapping of organised and opportunistic screening are context factors that minimise the advantages and maximise the costs of direct mailing: we must ship many self-samplers to nonresponders, but only a few under-covered women are the real target of the intervention. We tried to reduce costs sending the samplers only to women who were interested and requested it, but this strategy had a worse participation rate than standard recall letters. In this trial, we did not investigate self-sampling strategies that might strongly reduce the workload for midwives, 
that is, not targeted only to non-responders, but also to all the target population.

\section{CONCLUSIONS}

Self-sampling for HPV testing is acceptable to women and mailing a device for HPV DNA self-collection to non-responders to cervical cancer screening may increase compliance as compared with standard recall letters. Nevertheless, effectiveness is context specific. On top of this, the strategy is very

\section{REFERENCES}

Anhang R, Nelson JA, Telerant R, Chiasson MA, Wright Jr TC (2005) Acceptability of self-collection of specimens for HPV DNA testing in an urban population. Womens Health (Larchmt) 14: 721-728

Arbyn M, Anttila A, Jordan J, Ronco G, Schenck U, Segnan N, Wiener H, Herbert A, von Karsa L (2008) European Guidelines for Quality Assurance on Cervical Cancer Screening 2nd edn. European Community: Brussels; Office for Official Publications of the European Communities: Luxembourg

Bauer HM, Greer CE, Manos MM (1992) Determination of genital human papillomavirus infection by consensus polymerase chain reaction amplification. In Diagnostic Molecular Pathology, A Practical Approach, Herrington CS, McGee JOD (eds), pp 131 - 152. IRL Press: Oxford, UK

Belinson JL, Qiao YL, Pretorius RG, Zhang WH, Rong SD, Huang MN, Zhao FH, Wu LY, Ren SD, Huang RD, Washington MF, Pan QJ, Li L, Fife D (2003) Shanxi Province cervical cancer screening study II: selfsampling for high-risk human papillomavirus compared to direct sampling for human papillomavirus and liquid based cervical cytology. Int J Gynecol Cancer 13: 819-826

Bos AB, Rebolj M, Habbema JD, van Ballegooijen M (2006) Non-attendance is still the main limitation for the effectiveness of screening for cervical cancer in the Netherlands. Int J Cancer 119: 2372-2375

Bouvard V, Baan R, Straif K, Grosse Y, Secretan B, El Ghissassi F, Benbrahim-Tallaa L, Guha N, Freeman C, Galichet L, Cogliano V, WHO International Agency for Research on Cancer Monograph Working Group (2009) A review of human carcinogens - Part B: biological agents. Lancet Oncol 10: $321-322$

Brink AA, Meijer CJ, Wiegerinck MA, Nieboer TE, Kruitwagen RF, van Kemenade F, Fransen Daalmeijer N, Hesselink AT, Berkhof J, Snijders PJ (2006) High concordance of results of testing for human papillomavirus in cervicovaginal samples collected by two methods, with comparison of a novel self-sampling device to a conventional endocervical brush. J Clin Microbiol 44: 2518 - 2523

Bulkmans NW, Berkhof J, Rozendaal L, van Kemenade FJ, Boeke AJ, Bulk S, Voorhorst FJ, Verheijen RH, van Groningen K, Boon ME, Ruitinga W, van Ballegooijen M, Snijders PJ, Meijer CJ (2007) Human papillomavirus DNA testing for the detection of cervical intraepithelial neoplasia grade 3 and cancer: 5-year follow-up of a randomised controlled implementation trial. Lancet 370: $1764-1772$

Ciatto S, Grazzini G, Cecchini S, Iossa A (1993) Screening history of incident cases of invasive carcinoma of the cervix. Florence district 1988-1989. Tumori 79: $311-313$

Corkrey R, Parkinson L, Bates L (2005) Pressing the key pad: trial of a novel approach to health promotion advice. Prev Med 41: 657-666

Cuzick J, Arbyn M, Sankaranarayanan R, Tsu V, Ronco G, Mayrand MH, Dillner J, Meijer CJ (2008) Overview of human papillomavirus-based and other novel options for cervical cancer screening in developed and developing countries. Vaccine 26: K29-K41

Cuzick J, Clavel C, Petry KU, Meijer CJ, Hoyer H, Ratnam S, Szarewski A, Birembaut P, Kulasingam S, Sasieni P, Iftner T (2006) Overview of the European and North American studies on HPV testing in primary cervical cancer screening. Int J Cancer 119: 1095-1101

Eaker S, Adami HO, Granath F, Wilander E, Sparén P (2004) A large populationbased randomized controlled trial to increase attendance at screening for cervical cancer. Cancer Epidemiol Biomarkers Prev 13: 346-354

Giorgi Rossi P, Brezzi S, Esposito G, Brachini A, Raggi P, Federici A (2006) Estimation of Pap-test coverage in an area with an organised screening program: challenges for survey methods. BMC Health Ser Res 6: 36

Gök M, Heideman DA, van Kemenade FJ, Berkhof J, Rozendaal L, Spruyt JW, Voorhorst F, Beliën JA, oviæ M, Snijders PJ, Meijer CJ (2010) expensive in terms of number of self-samplers needed per screened woman.

\section{ACKNOWLEDGEMENTS}

The study was financed with funds from a project of Italian Ministry of Health aimed at supporting applied research to screening programmes (http://www.asrabruzzo.it/aree.php?id = 46). We thank Giovanna Patrone for the proof reading and editing of the final text.

HPV testing on self collected cervicovaginal lavage specimens as screening method for women who do not attend cervical screening: cohort study. BMJ 340: c1040

IARC Working Group on the Evaluation of Cancer Preventive Strategies (2005) Cervix Cancer Screening. IARC Handbooks of Cancer Prevention. IARC: Lyon

Ingemann-Hansen O, Lidang M, Niemann I, Dinesen J, Baandrup U, Svanholm H, Petersen L (2008) Screening history of women with cervical cancer: a 6-year study in Aarhus, Denmark. Br J Cancer 98: 1292-1294

ISTAT (2006) La prevenzione dei tumori femminili in Italia: il ricorso a pap test e mammografia. Anni 2004-2005. ISTAT: Roma (available at: http:// www.istat.it/salastampa/comunicati/non_calendario/20061204_00/)

Janerich DT, Hadjimichael O, Schwartz PE, Lowell DM, Meigs JW, Merino MJ, Flannery JT, Polednak AP (1995) The screening histories of women with invasive cervical cancer, Connecticut. Am J Public Health 85: $791-794$

Jensen H, Svanholm H, Støvring H, Bro F (2009) A primary healthcare-based intervention to improve a Danish cervical cancer screening programme: a cluster randomised controlled trial. J Epidemiol Community Health 63: $510-515$

Leyden WA, Manos MM, Geiger AM, Weinmann S, Mouchawar J, Bischoff K, Yood MU, Gilbert J, Taplin SH (2005) Cervical cancer in women with comprehensive health care access: attributable factors in the screening process. J Natl Cancer Inst 97: 675-683

Morrell S, Taylor R, Wain G (2005) A study of Pap test history and histologically determined cervical cancer in NSW women, 1997-2003. J Med Screen 12: $190-196$

Naucler P, Ryd W, Törnberg S, Strand A, Wadell G, Elfgren K, Rådberg T, Strander B, Johansson B, Forslund O, Hansson BG, Rylander E, Dillner J (2007) Human papillomavirus and Papanicolaou tests to screen for cervical cancer. $N$ Engl J Med 357: 1589-1597

Nobbenhuis MA, Helmerhorst TJ, van den Brule AJ, Rozendaal L, Jaspars LH, Voorhorst FJ, Verheijen RH, Meijer CJ (2002) Primary screening for high risk HPV by home obtained cervicovaginal lavage is an alternative screening tool for unscreened women. J Clin Pathol 55: 435-439

Ogilvie G, Krajden M, Maginley J, Isaac-Renton J, Hislop G, Elwood-Martin R, Sherlock C, Taylor D, Rekart M (2007) Feasibility of self-collection of specimens for human papillomavirus testing in hard-to-reach women. CMAJ 177: $480-483$

PASSI (2009) Sistema di sorveglianza PASSI. Rapporto nazionale 2008. Iacobelli: Pavona (available at: http://www.epicentro.iss.it/passi/ )

Petignat P, Faltin DL, Bruchim I, Tramèr MR, Franco EL, Coutlée F (2007) Are self-collected samples comparable to physician-collected cervical specimens for human papillomavirus DNA testing? A systematic review and meta-analysis. Gynecol Oncol 105: 530-535

Ronco G, Giorgi-Rossi P, Carozzi F, Confortini M, Dalla Palma P, Del Mistro A, Ghiringhello B, Girlando S, Gillio-Tos A, De Marco L, Naldoni C, Pierotti P, Rizzolo R, Schincaglia P, Zorzi M, Zappa M, Segnan N, Cuzick J, New Technologies for Cervical Cancer screening (NTCC) Working Group (2010) Efficacy of human papillomavirus testing for the detection of invasive cervical cancers and cervical intraepithelial neoplasia: a randomised controlled trial. Lancet Oncol 11: 249-257

Ronco G, Giubilato P, Naldoni C, Zorzi M, Anghinoni E, Scalisi A, Dalla Palma P, Zanier L, Barca A, Angeloni C, Prandini S, Maglietta R, Mancini E, Pizzuti R, Iossa A, Segnan N, Zappa M (2008) Extension of organised cervical cancer screening programmes in Italy and their process indicators. Epidemiol Prev 32: $37-54$

Ronco G, Segnan N, Giorgi-Rossi P, Zappa M, Casadei GP, Carozzi F, Dalla Palma P, Del Mistro A, Folicaldi S, Gillio-Tos A, Nardo G, Naldoni C, 
Schincaglia P, Zorzi M, Confortini M, Cuzick J, New Technologies for Cervical Cancer Working Group (2006) Human papillomavirus testing and liquid-based cytology: results at recruitment from the new technologies for cervical cancer randomized controlled trial. J Natl Cancer Inst 98: $765-774$

Salmerón J, Lazcano-Ponce E, Lorincz A, Hernández M, Hernández $\mathrm{P}$ Leyva A, Uribe M, Manzanares H, Antunez A, Carmona E, Ronnett BM, Sherman ME, Bishai D, Ferris D, Flores Y, Yunes E, Shah KV (2003) Comparison of HPV-based assays with Papanicolaou smears for cervical cancer screening in Morelos State, Mexico. Cancer Causes Control 14: $505-512$

Sankaranarayanan R, Nene BM, Shastri SS, Jayant K, Muwonge R, Budukh AM, Hingmire S, Malvi SG, Thorat R, Kothari A, Chinoy R, Kelkar R, Kane S, Desai S, Keskar VR, Rajeshwarkar R, Panse N, Dinshaw KA (2009) HPV screening for cervical cancer in rural India. $N$ Engl J Med 360: 1385 - 1394

Sanner K, Wikström I, Strand A, Lindell M, Wilander E (2009) Self-sampling of the vaginal fluid at home combined with high-risk HPV testing. Br J Cancer 101: $871-874$

Sasieni PD, Cuzick J, Lynch-Farmery E (1996) Estimating the efficacy of screening by auditing smear histories of women with and without cervical cancer. The National Co-ordinating Network for Cervical Screening Working Group. Br J Cancer 73: $1001-1005$

Stewart DE, Gagliardi A, Johnston M, Howlett R, Barata P, Lewis N, Oliver T, Mai V (2007) HPV Self-collection Guidelines Panel.

\section{APPENDIX}

Members of the Self-Sampling Study working group:

Rome: Paolo Giorgi Rossi, Alessandra Sperati, Laura Camilloni, Laila Maria Marsili, Paola Capparucci, Concetta Bellanova and
Self-collected samples for testing of oncogenic human papillomavirus: a systematic review. J Obstet Gynaecol Can 29: $817-828$

Sundhedsstyrelsen - Center for Evaluering og MTV (2005) Veeskebaseret teknik og udstrygningsteknik anvendt til screening for livmoderhalskreft i Danmark: en medicinsk teknologivurdering. Report No. 7(3). Sundhedsstyrelsen - Center for Evaluering og Medicinsk Teknologivurdering: København

Sung HY, Kearney KA, Miller M, Kinney W, Sawaya GF, Hiatt RA (2000) Papanicolaou smear history and diagnosis of invasive cervical carcinoma among members of a large prepaid health plan. Cancer 88: $2283-2289$

Szarewski A, Cadman L, Mallett S, Austin J, Londesborough P, Waller J, Wardle J, Altman DG, Cuzick J (2007) Human papillomavirus testing by self-sampling: assessment of accuracy in an unsupervised clinical setting. J Med Screen 14: 34-42

van der Graaf Y, Zielhuis GA, Peer PG, Vooijs PG (1988) The effectiveness of cervical screening: a population-based case-control study. J Clin Epidemiol 41: $21-26$

Waller J, McCaffery K, Forrest S, Szarewski A, Cadman L, Austin J, Wardle J (2006) Acceptability of unsupervised HPV self-sampling using written instructions. J Med Screen 13: $208-213$

Wright Jr TC, Denny L, Kuhn L, Pollack A, Lorincz A (2000) HPV DNA testing of self-collected vaginal samples compared with cytologic screening to detect cervical cancer. JAMA 283: 81-86

Piero Borgia; Abruzzo: Claudio Angeloni, Amedeo Lattanzi, Tatiana Reggi, Patrizia Bruni and Clara Monaco; Florence: Anna Iossa, Massimo Confortini, Francesca Maria Carozzi, Elena Burroni, Giovanni Pontenani, Carmen Beatriz Visioli, Cristina Sani, Carmelina Di Pierro and Elisa Sereno. 